\title{
COMPOSITE COATINGS WITH CERAMIC MATRIX INCLUDING NANOMATERIALS AS SOLID LUBRICANTS FOR OIL-LESS AUTOMOTIVE APPLICATIONS
}

\begin{abstract}
The paper presents the theoretical basis of manufacturing and chosen applications of composite coatings with ceramic matrix containing nanomaterials as a solid lubricant $(\mathrm{AHC}+\mathrm{NL})$. From a theoretical point of view, in order to reduce the friction coefficient of sliding contacts, two materials are required, i.e. one with a high hardness and the other with low shear strength. In case of composite coatings $\mathrm{AHC}+\mathrm{NL}$ the matrix is a very hard and wear resistant anodic oxide coating (AHC) whereas the solid lubricant used is the nanomaterial (NL) featuring a low shear strength such as glassy carbon nanotubes (GC). Friction coefficient of cast iron GJL-350 sliding against the coating itself is much higher $(0.18-0.22)$ than when it slides against a composite coating (0.08-0.14). It is possible to reduce the friction due to the presence of carbon nanotubes, or metal nanowires.

Keywords: composite coatings, nanotubes, nanowires, solid lubricants
\end{abstract}

\section{Introduction}

Most of mechanical and thermal loads in contacts of machine parts used in automotive industry are transmitted to the bulk material via surface layer (SL). A special type of load is the friction, which takes place direct in the surface layer. This is the reason, why the producer of machinery parts form such a SL, which would carry any required loads. A monomaterials (bulk) SL on engineering materials designed for production of technical means of transport fails to carry such loads and will be to expensive. To make the vehicles qualitatively and price competitive composite coatings should be applied in machine parts production. The surface layer have to mitigate friction and wear intensity. It is possible due to a formation of a permanent boundary lubricant layer, provided the pairing is lubricated with oil or greases. In vehicles, including engines and air compressors, the aim is to replace the oils and greases with solid lubricants [1-4]. To maintain the lubricating properties of oils (viscosity) it is necessary to ensure a proper cooling of compressors and engines which would result in their lower performance. Therefore, the research on introducing solid lubricants to the surface layer of the sliding parts of engines and compressors are being currently carried out. The surface layers sliding at elevated temperatures must feature good tribological properties. One of the materials that can operate at higher temperatures and retain its properties is a ceramic. The parts of engines and compressors are made, in most cases, of aluminum alloy. Therefore, the formation of ceramic surface layer upon such components is possible by the electrolytic oxidation. The production technology principles and selected properties of composite coatings with ceramic matrix including nanomaterials as solid lubricants (glassy carbon nanotubes and metal nanowires) will be presented in this paper.

\section{Theoretical basis}

From tribological point of view the basic criterion for designing composite coatings including nanomaterials as solid lubricants is the friction hypothesis elaborated by Ernst and Merchant [2], which helps to calculate the friction coefficient. According to this hypothesis the friction coefficient in sliding contact can be calculated from the following equation:

$$
\mu=\frac{\tau}{H}+\operatorname{tg} \alpha
$$

where:

$\tau$ - mean shear strength of the adhesion junction in the contact zone [MPa], usually the shear strength of the weaker material (shearing takes place only inside glassy carbon layers with shear strength: $\tau=30 \mathrm{MPa}$ or inside $\mathrm{Cu}$ nanowires with $\tau=5-110 \mathrm{MPa}$ [5]);

$H$ - hardness of the hardest material in pairing (AHC 450-500 MPa);

$\alpha$ - mean angle of inclination of real contact areas to the direction of tangent force, equal to the angle of inclination of roughness peaks (the cast iron surface is worn-in, with very low roughness, AHC could be polished which would reduce the roughness).

\footnotetext{
* SILESIAN UNIVERSITY OF TECHNOLOGY, FACULTY OF TRANSPORT, KATOWICE, POLAND

** SILESIAN UNIVERSITY OF TECHNOLOGY, FACULTY OF MATERIALS ENGINEERING AND METALLURGY, KATOWICE, POLAND 
The shear strength of copper nanowires depends on the temperature which grows as a result of friction. $\mathrm{Cu}$ nanowires with good thermal conductivity $(\lambda=380 \mathrm{~W} / \mathrm{mK})$ closed inside aluminum oxide cells (Fig. 1) with poor thermal conductivity $(\lambda=24 \mathrm{~W} / \mathrm{mK})$ rapidly increase their temperature. As a result, their shear strength decreases (Fig. 2). The graphic interpretation of the friction coefficient depending on the hardness of the anodic oxide coating and shear strength, calculated by the formula (1) is shown in Figure 3. In order to determine the friction coefficient, AHC hardness from the range 450-500 $\mathrm{MPa}$ (arrow 1) and the shear strength of copper from $5 \mathrm{MPa}$ at $800^{\circ} \mathrm{C}$ to $110 \mathrm{MPa}$ at $20^{\circ} \mathrm{C}$ (arrow 2) should be assumed. From the point of intersection, the straight line (arrow 3 ) has to be cut to the intersection with the plane of the chart. The intersection of the line (arrow 4) with the axis of the friction coefficient gives its value $(0.15$ for the assumed pair $H$ and $\tau$ ).

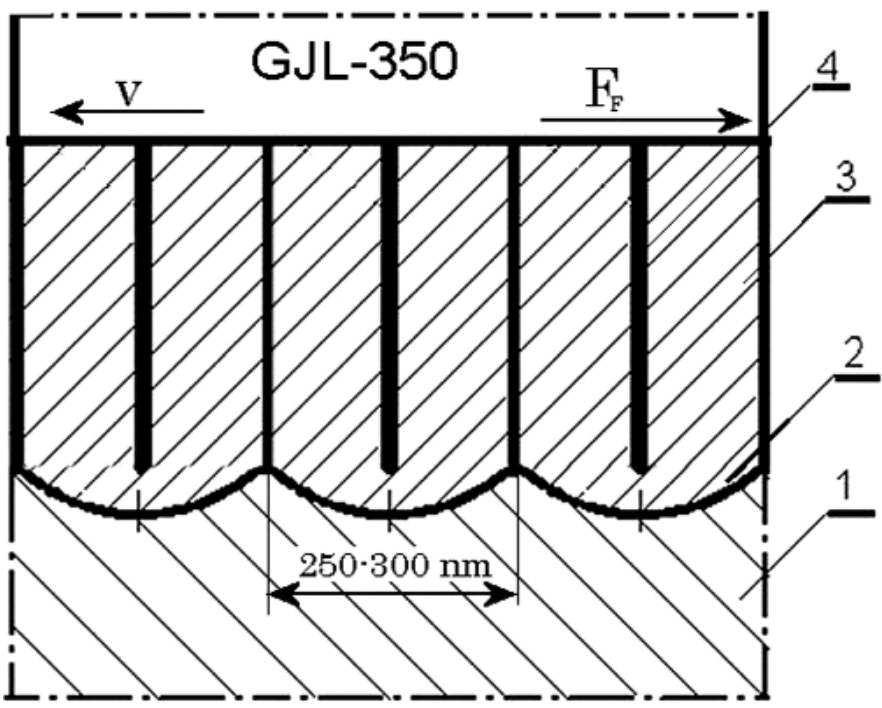

Fig. 1. Model of cast iron-composite coating contact: 1 - oxidized aluminum alloy, 2 - barrier layer, 3 - porous layer, 4 - metal nanowires/ carbon nanotubes, $v$ - sliding direction, $F_{F}$ - friction force

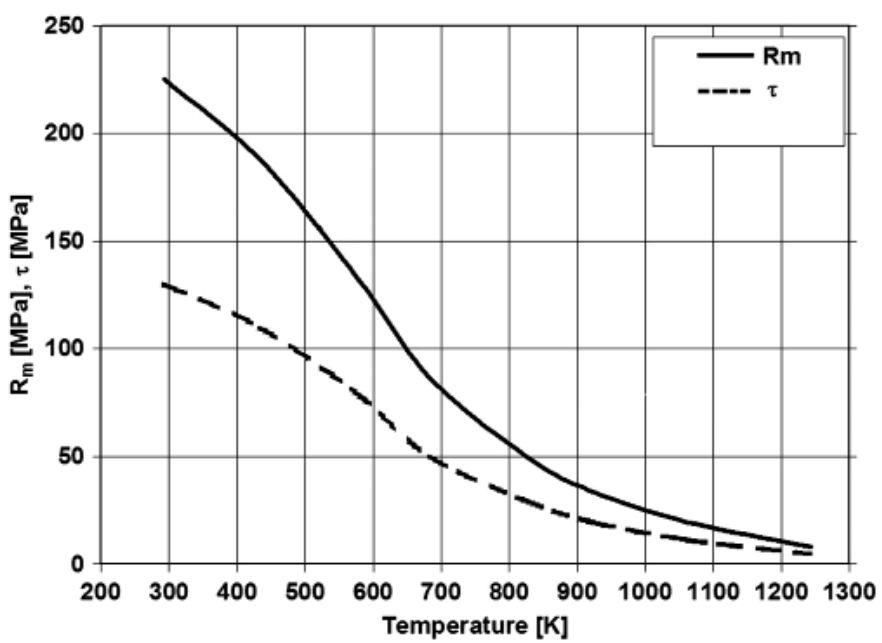

Fig. 2. Dependence of copper tensile strength $\left(R_{m}\right)$ and shear strength $(\tau)$ on temperature

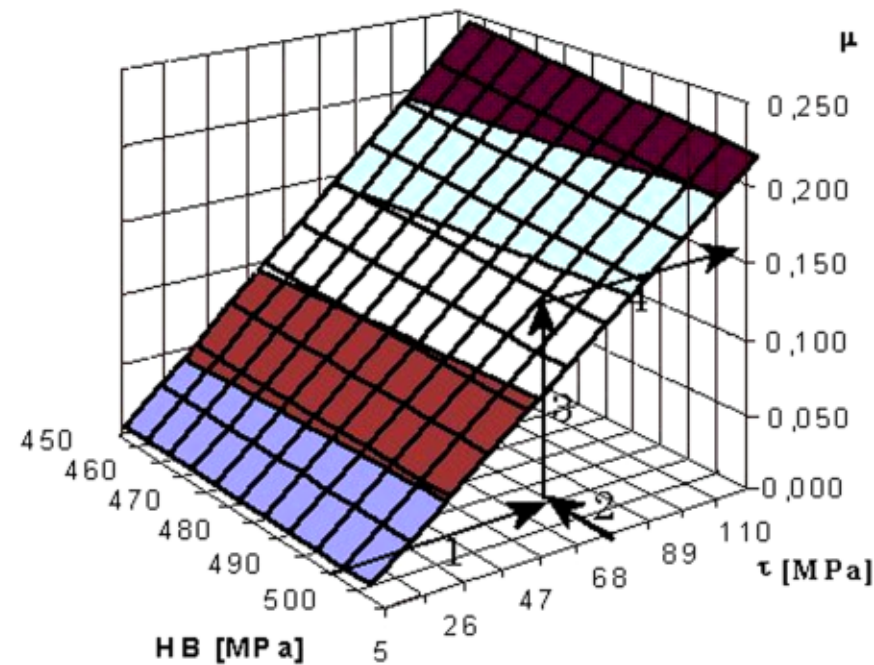

Fig. 3. Friction coefficient $(\mu)$ v. AHC hardness (HB) and $\mathrm{Cu}$ shear strength $(\tau)$ calculated according to Ernst and Merchant hypothesis

The properties of carbon nanotubes can be shaped by the selected conditions of the pyrolysis of a precursor introduced into the pores of the oxide coating. Pyrolysis temperature and time help regulate the shear strength of the glassy carbon used as the material for nanotubes $[4,6,7]$.

\section{Experimental details}

The anodic oxide layer constitutes the matrix of the coatings. Due to the porous structure of anodic oxide layer (Fig. 4) a synthesis of carbon nanotubes (Figs. 5, and 6a) and metal nanowires (Fig. 6b) in the pores of oxide cells is possible.

The synthesis of carbon nanotubes has been conducted due to bringing of liquid substance (polymer of polyfurfuryl alcohol in the presence of a catalyst, e.g., hydrochloric acid) including carbon into the pores and its carbonization in argon atmosphere at temperature of $1000^{\circ} \mathrm{C}$ [4]. The result of this is a composite coating with very hard, wear resistant oxide coating with regularly distributed glassy carbon nanotubes (9-16 CNTs per $\mu \mathrm{m}^{2}$ ) which serve as a lubricant reducing friction and wear. Such coating can be used in machine pairings operating under conditions where lubricants cannot be used, for example in electronic and aerospace industry as well as in oil-less compressors in technical means of transport.

The synthesis of nickel or copper nanowires has been conducted due to bringing $\mathrm{Ni}$ or $\mathrm{Cu}$ ions into the pores by electrolytic metallization. As a result a composite coating $\mathrm{AHC}+\mathrm{Me}$ is obtained [5].

On the surface of the samples after pyrolysis a continuous film of glassy carbon was formed but was partially removed during cast iron sliding (Fig. 7b). Carbon nanotubes were produced inside the pores and were visible only after the oxide layer had been dissolved (Fig. 6a). Metal nanowires have been formed inside the pores of $\mathrm{AHC}+\mathrm{Me}$ layers (Fig. 6b). They are visible after ion etching. 
a)

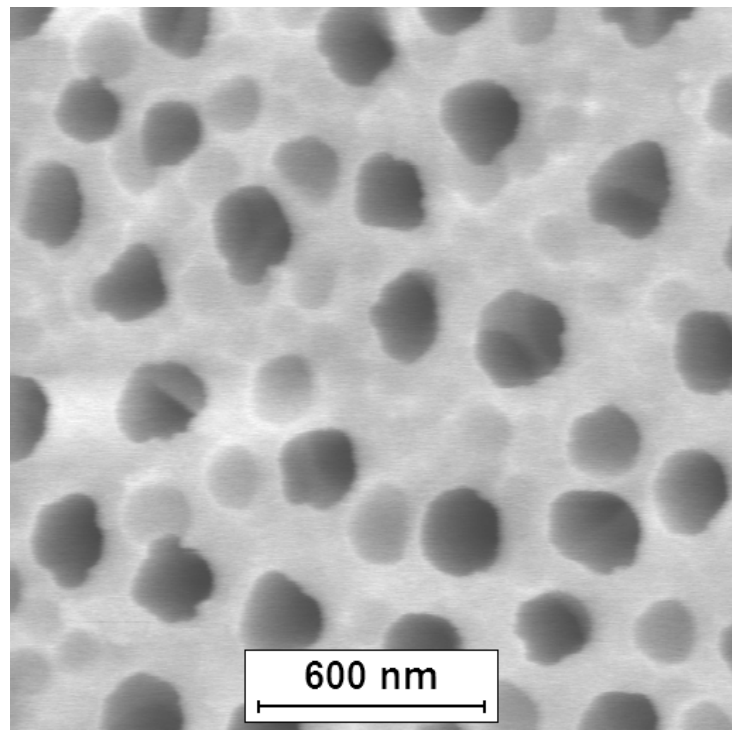

b)

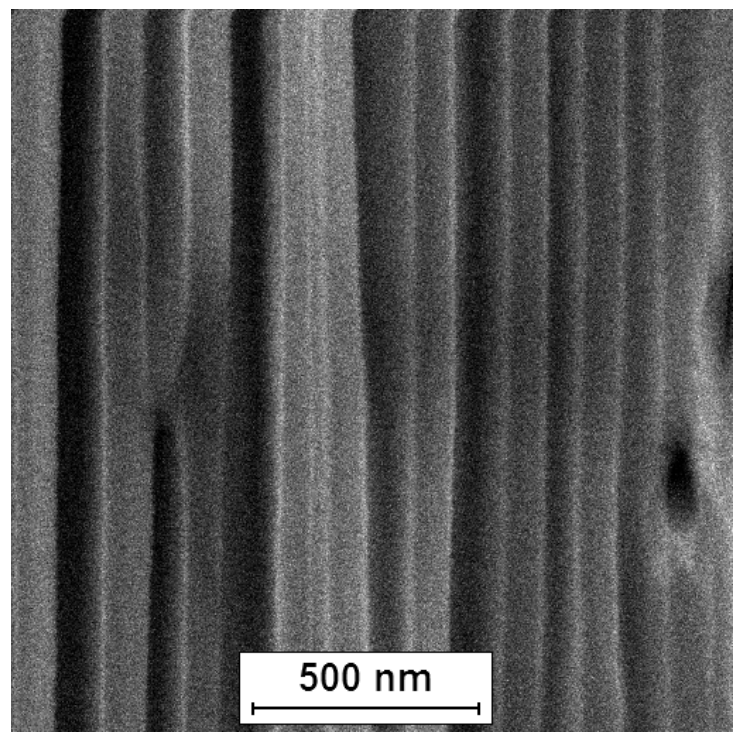

Fig. 4. Anodic oxide coating as a matrix for composite coating: a - surface view, b - fracture (SEM)

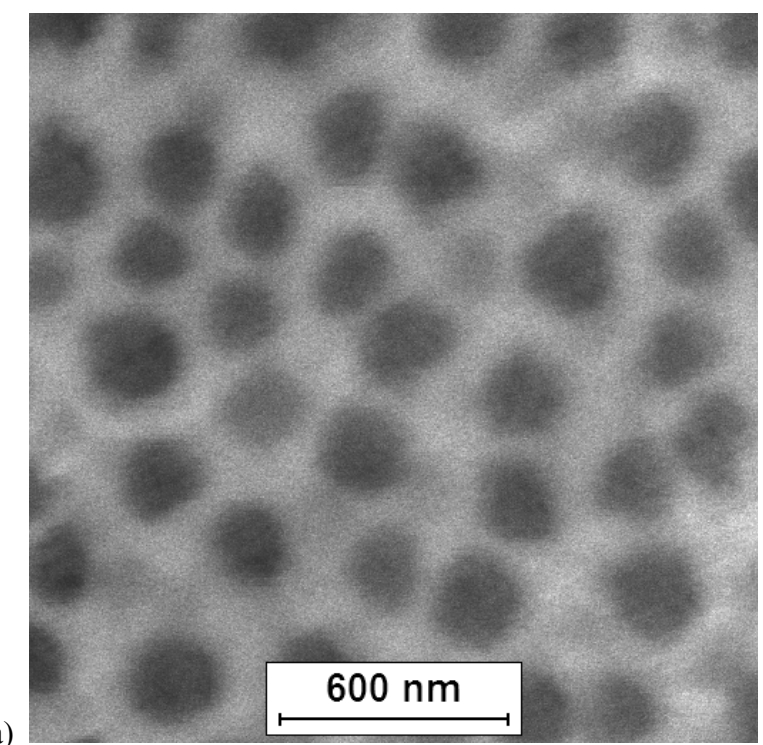

a)

Fig. 5. Composite coating with anodic oxide layer as a matrix and carbon nanotubes as solid lubricant: $a-$ surface view, $b-$ fracture (SEM)

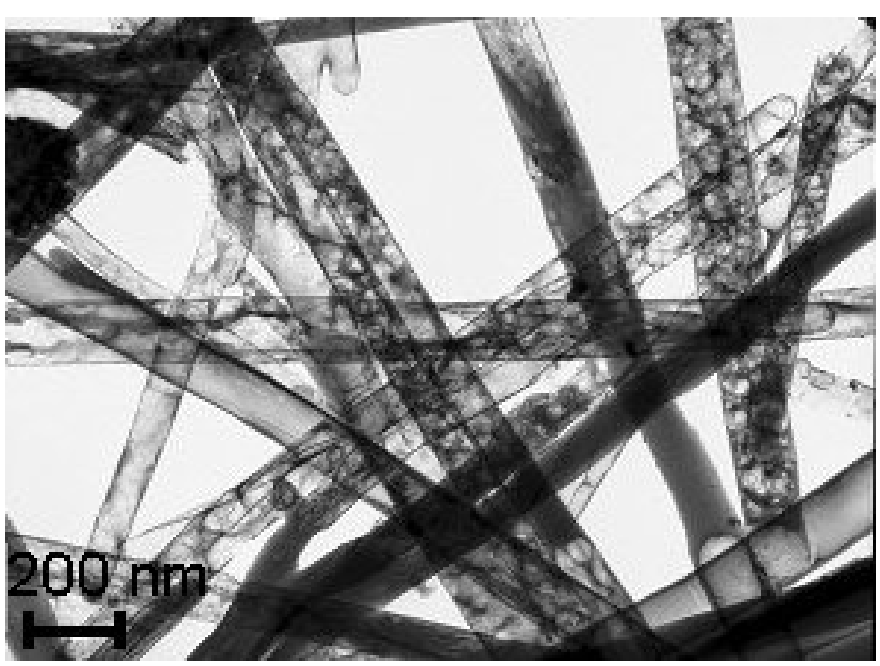

a)

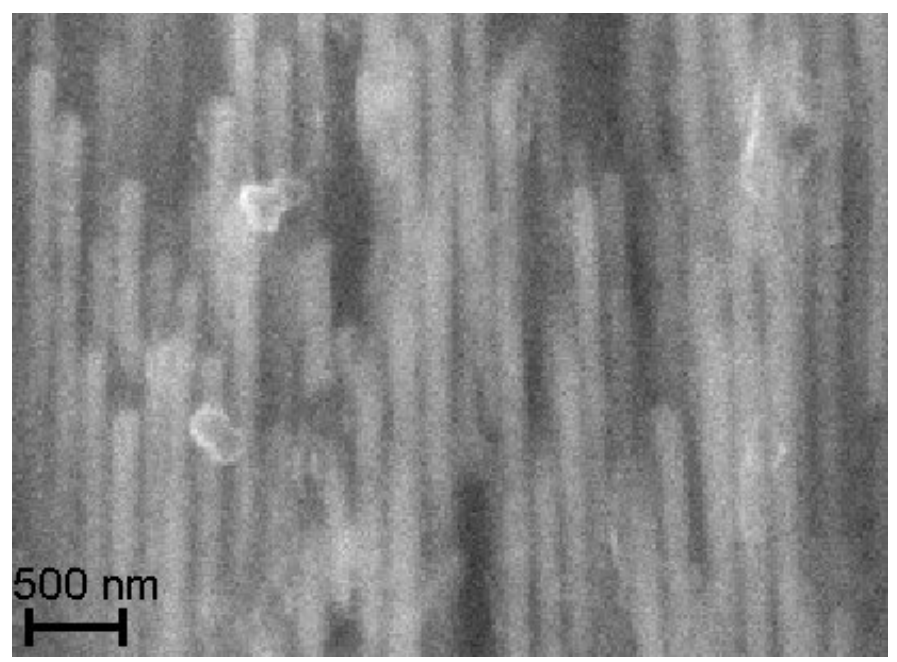

b)

Fig. 6. Glassy carbon nanotubes (a) and nickel nanowires (b) synthesized in the pores of anodic hard coating 


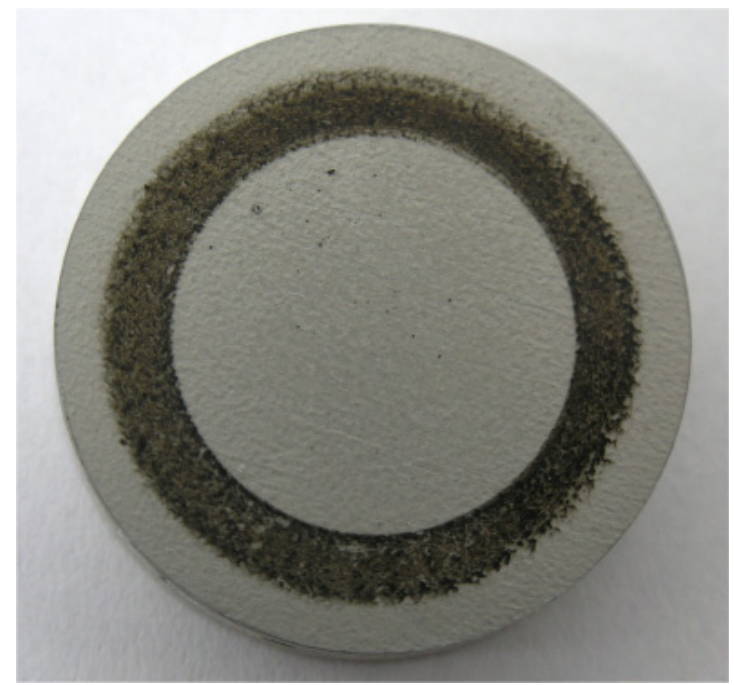

a)

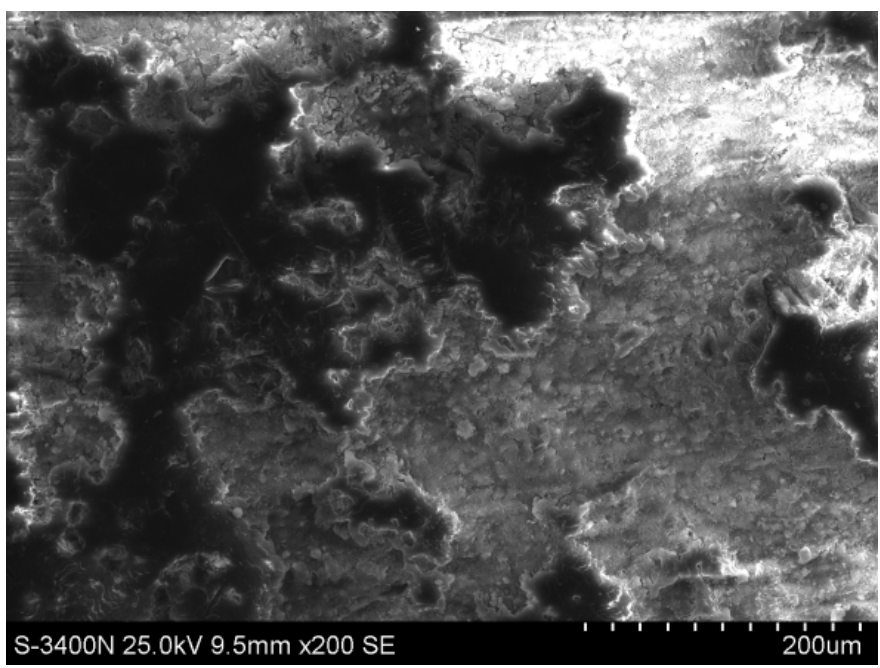

a)

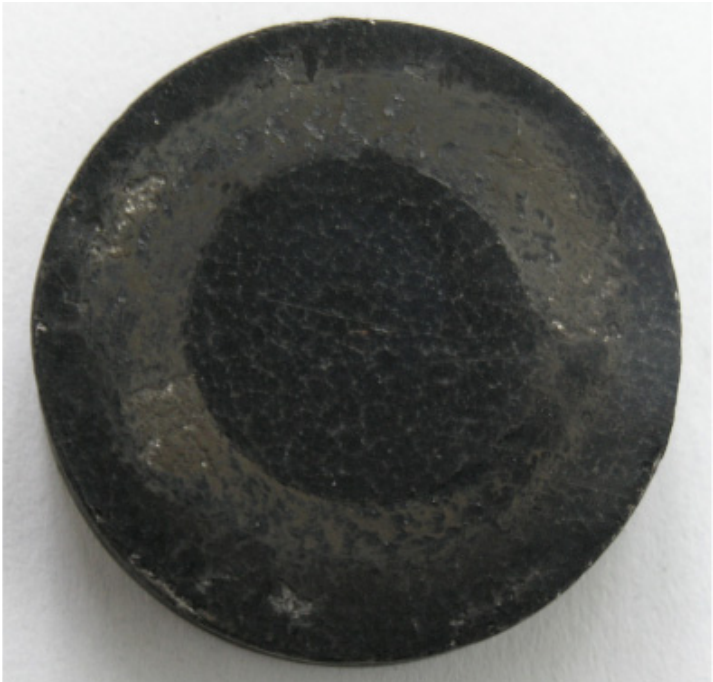

b)

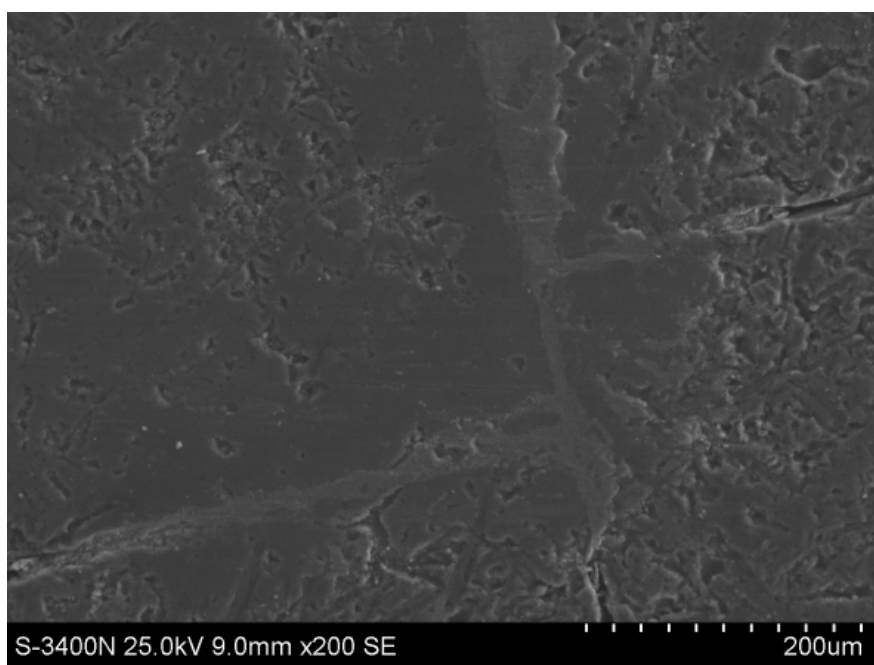

b)

Fig. 7. Surface of AHC (a, c - SEM) and composite coating AHC $+\mathrm{GC}(\mathrm{b}, \mathrm{d}-\mathrm{SEM})$ on AW-6061 aluminium alloy after sliding against cast iron

The elaborated composite coating - shortly named $\mathrm{AHC}+\mathrm{GC}-$ has been formed on machines parts destined for oil less pairings. These investigated parts in a form of discs have been made of aluminium alloy EN-AW-6061. EN-GJL-350 cast iron, used for piston rings, has been chosen as a sliding partner. The tribological investigations of $\mathrm{AHC}+\mathrm{GC}$ composite coatings have been carried out on tribological tester T11 (pin on disc) in air at ambient temperature, with relative humidity of $60 \%$ by unit pressure $p=0.8 \mathrm{MPa}$ and sliding velocity $v=1 \mathrm{~m} / \mathrm{s}$. Friction force have been measured using strain gauge with an inaccuracy of $3 \%$. To be able to evaluate the investigated layer, the comparative investigations of anodic hard coating (AHC) without glassy carbon nanotubes have been carried out.

\section{Results and discussion}

The obtained samples were subjected both to microscopic examination in order to determine their structure and to tribo- logical tests to specify the effect of carbon nanotubes upon the friction coefficient. Depending on the oxidation conditions, oxide coatings were obtained with pores diameters ranging from 30 to $150 \mathrm{~nm}$. Average diameters of oxide cells are 50 and $300 \mathrm{~nm}$ respectively. Surface participation of oxide cells was 400-50 cells for $1 \mu \mathrm{m}^{2}$ of the surface. Coatings with pores of a smaller diameter are more useful for tribological purposes, since the wall thickness of oxide cells is greater and increases both the hardness of coating and its resistance to wear. In consequence of the formation of nanotubes inside the pores of the oxide coating, the pores diameters was reduced which is reflected on the surface of the composite coating (Fig. 5a)

The registered friction coefficient during sliding of cast iron, against $\mathrm{AHC}+\mathrm{GC}$ was lower $(\mu=0.08-0.14)$ than the one in pairing cast iron/AHC (0.18-0.22).

On the surface of the composite coatings after friction, a thin film of glassy carbon was left (Figs. 7b, d), which enabled to maintain the friction coefficient value of 0.14 . On the surface of the $\mathrm{AHC}$ after friction an extremely thin, discontinuous layer 
of graphite, originating from the cast iron wear products, was formed (Figs. 7a, c). Therefore, the friction coefficient was higher and amounted to 0.22 . A comparison of friction coefficients indicates that the presence of carbon nanotubes in the oxide significantly reduces the friction. The results of laboratory tests made it possible to use composite coatings $\mathrm{AHC}+\mathrm{GC}$ to cover the liners of sleeve cylinders in the oil less compressor and the internal combustion engine (Fig. 8)

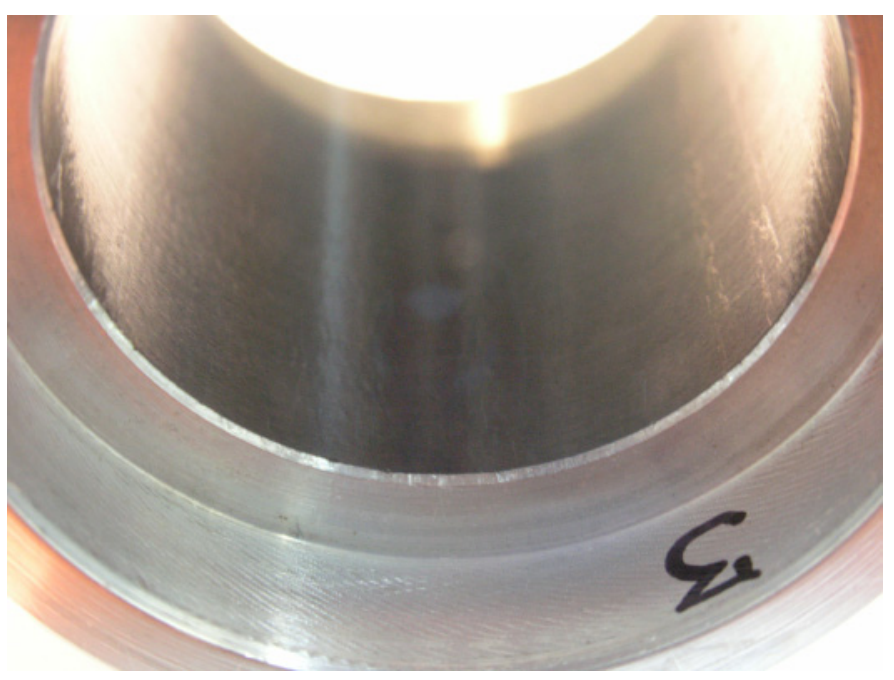

a)

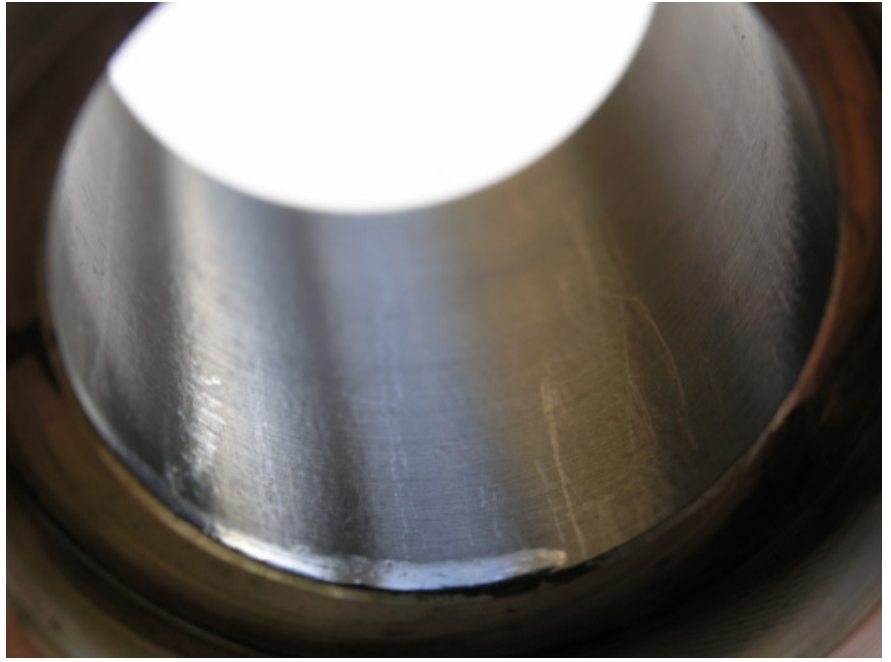

b)

Fig. 8. Cylinder for oil less compressor before coating (a) and after coating with $\mathrm{AHC}+\mathrm{GC}$ composite layer

\section{Conclusions}

The carried out research confirmed that the production of composite coatings with ceramic matrix, both with carbon nanotubes and metal nanowires, is possible. The use of glassy carbon nanotubes as a solid lubricant filling the pores in the anodic oxide coating fulfills its role, ie. reduces the friction forces during the rubbing of the coating against cast iron in air (without of lubricant). Currently, the research on these coatings in oil less compressors of air conditioners and external combustion engines are being performed. The manufactured composite coatings containing metal nanowires $(\mathrm{AHC}+\mathrm{Me})$ have been tested under limited lubrication and soon will be tested in friction in air conditions. The results will be published in the next paper.

\section{REFERENCES}

[1] J. Szajnar, A. Walasek, C. Baron, Archives of Metallurgy and Materials. 58(3), 931-936 (2013).

[2] H. Ernst, An Interpretive Review of $20^{\text {th }}$ Century Machining and Grinding Research. TechSolve Inc. Cincinati (OH) 2003.

[3] A. Posmyk, Surface and Coatings Technology 206 (15), 3342-3349 (2012).

[4] A. Posmyk, H. Wistuba, Archives of Metallurgy and Materials. 56 (4), 909-917 (2011).

[5] A. Posmyk, Surface Engineering, 29 (3), 171-176 (2013).

[6] S. Lee. G.H. Gu, H. Kim, at all, Chem. Mater. 13, 2387-2391 (2001).

[7] A.B. Fuertes, Carbon 40, 1600-1602 (2002).

\section{Acknowledgements}

Financial support of structural Funds in the Operational Programme -Innovative Economy (IEOP) financed from the European Regional Development Fund Project No POIG.0101.02-00-015/08 is gratefully acknowledged. 